\title{
Vivência de violência entre escolares brasileiros: resultados da Pesquisa Nacional de Saúde do Escolar (PeNSE)
}

\author{
Violence exposures by school children in Brazil: results from the \\ National Adolescent School-based Health Survey (PeNSE)
}

\author{
Deborah Carvalho M alta ${ }^{1}$ \\ Edinilsa Ramos deSouza ${ }^{2}$ \\ M arta M aria Alves da Silva ${ }^{1}$ \\ Carlos dos Santos Silva ${ }^{2}$ \\ M arco Antonio Ratzsch de Andreazzi ${ }^{3}$ \\ Claudio Crespo $^{3}$ \\ Márcio Dênis M edeiros M ascarenhas ${ }^{1}$ \\ Denise Lopes Porto ${ }^{4}$ \\ Alba Lucy Giraldo Figueroa ${ }^{1}$ \\ Otaliba Libânio de M orais $\mathrm{N}$ eto ${ }^{4}$ \\ Gerson de Oliveira Penna ${ }^{4}$
}

${ }^{1}$ Coordenação Geral de Vigilância de Doençase Agravos Não

Transmissíveis, Secretaria deVigilância em Saúde, M inistério da Saúde. SAF Sul, trecho 2 , lote $5 / 6$, torre I, edifício Premium, sala 14, térreo. 70070-600 Brasília DF.

deborah.malta@saude.gov.br

${ }^{2}$ Escola Nacional deSaúde

Pública Sergio Arouca,

Fundação Oswaldo Cruz.

${ }^{3}$ Instituto Brasileiro de

Geografia e Estatística.

${ }^{4}$ Secretaria de Vigilância em

Saúde, M inistério da Saúde.
Abstract This article presents themain results of the National Adolescent School-based $\mathrm{H}$ ealth Survey (PeN SE). A questionnaire was applied to a sample of 60,973 students of the 9th year of J unior high school in public and private schools of the Brazilian state capitals and the Federal District, between $\mathrm{M}$ arch and June 2009. The prevalence and confidence interval of $95 \%(\mathrm{Cl} 95 \%)$ of the violence situations involving adolescents were analyzed. The following situations were identified: lack of safety on theway home school ( $6.4 \%$; CI95\%: 6.1\%-6.8\%) and at school (5.5\%; CI95\%: $5.2 \%-5.8 \%)$; involving fights with physical aggression (12.9\%; CI95\%: $12.4 \%-13.4 \%)$, with knife $(6.1 \% ; \mathrm{Cl} 95 \%$ : $5.7 \%-6.4 \%)$ or fire arm (4.0\%; Cl95\%: 3.7\%-4.3\%); physical aggression by family member (9.5\%; CI95\%: 9.1\%-9.9\%). Violence situations were more prevalent among malestudents. Thereweregreat variationsamong the cities studied. Adolescents are exposed to different violence manifestations in the institutions that supposedly must assure their protection and healthy development: school and thehome. These results aim to support health promotion measures and prevention of these risk factors.

Key words Violence, Child, Adolescent, School health, Adolescent behavior
Resumo Esteartigo apresenta os principais resultados da Pesquisa Nacional de Saúde do Escolar (PeNSE). A plicou-se questionário em uma amostra de conglomerados de 60.973 estudantes do 9o ano do ensino fundamental de escolas públicas e privadas das capitais dos estados brasileiros e do Distrito Federal, entre março e junho de 2009. Analisam-se prevalências e intervalos de confiança de 95\% (IC 95\%) das situações de violência envolvendo adolescentes. Foram identificadas as se guintes situações: insegurança no trajeto casa-escola $(6,4 \%$; IC $95 \%$ : 6,1\% - 6,8\%) ena escola ( $5,5 \%$; IC 95\%: 5,2\%-5,8\%); envolvimento em brigascom agressão física (12,9\%; I C95\% : 12,4\% - 13,4\%), com arma branca ( $6,1 \%$; IC $95 \%: 5,7 \%-6,4 \%$ ) ou arma de fogo (4,0\%; IC 95\% : 3,7\% - 4,3\%); agressão física por familiar (9,5\%; IC $95 \%$ : 9,1\%-9,9\%). As situações de violência foram mais prevalentes entre estudantes do sexo masculino. H ouve grande variação segundo as cidades estudadas. O sadolescentes estão expostos a diferentes manifestações de violência nas instituições que supostamente deveriam garantir sua proteção e desenvolvimento saudável e seguro - a escola e o lar. Esses resultados visam apoiar medi das de promoção à saúdee prevenção desses fatores de risco.

Palavras-chave Violência, Criança, Adolescente, Saúde escolar, Comportamento do adolescente 
Introdução

A violência assumiu grande importância para a sociedade brasileira nas últimas décadas e tornou-se um premente problema de saúde pública, em razão de sua magnitude, gravidade, impacto social e capacidade devulnerabilizar a saúdeindividual ecoletiva.

A Organização Mundial da Saúde (OMS) ${ }^{1}$ define a violência como o uso da força física ou do poder real ou em ameaça, contra si próprio, contra outra pessoa, ou contra um grupo ou uma comunidade, que resulte ou tenha qualquer possibilidade de resultar em lesão, morte, dano psicológico, deficiência de desenvolvimento ou privação.

Este é um fenômeno multicausal que possui forte correlação com desigualdades econômicas e socioculturais, mas também se relaciona com aspectos subjetivos e comportamentais vigentes em cada sociedade.

Segundo a $\mathrm{OMS}^{2}$, distinguem-se quatro tipos de violência contra crianças e adolescentes: físico, sexual, emocional ou psicológico e negligência, os quais podem resultar em danos físicos, psicológicos, além de danos ao seu crescimento, desenvolvimento e maturação.

Parte desses tipos de agressão pode ser identificada com a denominação de violência intrafamiliar, que se caracteriza por todo tipo de omissão que prejudica o bem-estar, a integridade física, psicológica, a liberdade ou direito de desenvolvimento de algum membro da família². 0 Estatuto da Criança e do Adolescente (ECA $)^{3}$, em vigor desde 1990, constitui uma das estratégias do Estado e da sociedade para preservar os direitos fundamentais da população brasileira nessas faixas etárias. O ECA assegura que nenhuma criança ou adolescente deve ser objeto de discriminação, negligência, exploração, violência, crueldade ou agressão dentro ou fora da família ${ }^{3}$.

No Brasil, crianças, adolescentes e jovens estão entre os grupos populacionais mais vitimizados pela violência, sendo essa sua principal causa de morbimortalidade $e^{4}$. Cotidianamente, os locais mais frequentes para essas ocorrências são a rua e o domicilio; a escola ocupa o terceiro lugar ${ }^{5}$. Entretanto, são poucos os estudos de abrangência nacional que mostram a diversidade das formas e os locais de ocorrência da violência que acomete as crianças e os adolescentes, tornando-se importante identificá-los, visando a sua preven ção.

Nesse sentido, a Pesquisa Nacional de Saúde do Escolar (PeN SE) tuto Brasileiro de Geografia e Estatística (IBGE) em parceria com o M inistério da Saúde, vem contribuir para o diagnóstico desituações deviolência vividas e percebidas por estudantes adolescentes.

0 objetivo do presente estudo é descrever as prevalências de percepção dos escolares sobre segurança no deslocamento para a escola e na escola, o envolvimento desse segmento com violência física, uso de arma branca e uso de arma de fogo, bem como violência/agressões perpetradas por familiares. Pretende-se, assim, meIhor compreender esse fenômeno e apoiar a tomada de decisão visando a sua prevenção.

\section{Métodos}

Os dados aqui apresentados provêm de um estudo transversal que foi realizado pelo IBGE em parceria com o M inistério da Saúde e envolveu escolares do 9o ano ( 8 a série) do ensino fundamental de escolas públicas e privadas das capitais dos estados brasileiros e do Distrito Federal, entre março e junho de 20096.

A amostra por conglomerados em dois estágios utilizou os dados do cadastro do Censo Escolar de 2007. No primeiro estágio foi feita a seleção das escolas e, no segundo, a seleção das turmas, entrevistando todos os alunos dentre as selecionadas 6 .

A amostra foi calculada para fornecer estimativas de proporções (ou prevalências) de algumas características de interesse, em cada um dos estratos geográficos (as 26 capitais dos estados e o Distrito Federal), com um erro máximo de 0,03 (3\%) em valor absoluto ao nível de confiança de $95 \%$.

Utilizou-seum questionário autoaplicável que versava sobre módulos temáticos acerca de diversos fatores de risco e proteção, como alimentação saudável; atividade física; uso de tabaco, álcool e outras drogas; acidentes de trânsito e violência, dentre outros. 0 questionário foi elaborado tomando-se como referências a pesquisa entre escolares Health Behaviour in Schoolaged Children ( $\mathrm{HBSC})^{7}$, da OMS, e outras pesquisas internacionais, como o Youth Risk Behavior Surveillance System (YRBSS) ${ }^{8}$ e nacionais ${ }^{9,10}$. 0 instrumento foi testado e adaptado para a realidade brasileira, tendo sido realizados prétestes em escolas do Rio de Janeiro (RJ), de Belém (PA) e Recife (PE), em 20086.

A plicou-se o questionário a todos os alunos das turmas selecionadas, usando-se um computador manual, o Personal Digital Assistant (PDA), operado pelo próprio aluno, que armazenava as 
informações automaticamente. Os dados eram armazenados ao longo do dia e depois transferidos para uma planilha única. Os alunos que não se sentiam motivados a participar da pesquisa foram considerados como perda.

Em 2007 foram selecionadas para a pesquisa 1.453 escolas e 2.175 turmas, nas quais havia 68.735 alunos frequentes e 63.411 estavam presentes no dia da coleta, totalizando 7,7\% de perdas nessa etapa. Foram excluídos da amostra 501 estudantes que se negaram a participar e os que não preencheram a variável sexo. Assim, foram analisados dados referentes a 60.973 escolares, com uma taxa de não resposta geral de $11,3 \%$.

N este artigo, são analisadas situações de violência envolvendo adolescentes, considerando os seguintes indicadores: (1) proporção de alunos que, nos últimos trinta dias, faltaram pelo menos um dia à escola por insegurança no trajeto casaescola; (2) proporção de alunos que, nos últimos trinta dias, faltaram pelo menos um dia à escola por insegurança na escola; (3) proporção de alunos que, nos últimos trinta dias, se envolveram em alguma briga com agressão física; (4) proporção de alunos que, nos últimos trinta dias, se envolveram em al guma briga com arma de fogo; (5) proporção de alunos que, nos últimos trinta dias, se envolveram em alguma briga com arma branca; (6) proporção de alunos agredidos fisicamente por algum adulto da família.

Foram calculados as prevalências e os intervalos de confiança de $95 \%$ (IC 95\%) para os eventos de interesse segundo sexo e dependência administrativa (escola pública ou privada) para o conjunto das 27 capitais, possi bilitando a identi- ficação de diferenças estatisticamente significativas. U tilizou-se o pacote estatístico SPSS ${ }^{11}$.

0 estudo foi aprovado pela Comissão Nacional deÉtica em Pesquisa (Conep) do M inistério da Saúde, sob a emenda no 005/2009 referente ao Registro $n$ o 11.537. A realização da pesquisa foi precedida de contato com as Secretarias Estadual e Municipal de Educação e com a direção das escolas selecionadas em cada município.

\section{Resultados}

A Tabela 1 apresenta o percentual de escolares do 9 o ano do ensino fundamental que vivenciaram algum tipo desituação de violência segundo sexo e dependência administrativa da escola para o conjunto de capitais de estados e Distrito Federal, em 2009. Observa-se que 6,4\% (IC95\%: $6,1 \%-6,8 \%)$ dos estudantes deixaram de ir à escola porque não se sentiam seguros no caminho de casa para a escola ou da escola para casa, variando de $6,0 \%$ (IC95\%: 5,5\%-6,5\%) a 6,9\% (IC95\%: 6,4\%-7,5\%) entre o sexo feminino e 0 masculino, respectivamente. A sensação de insegurança foi maior entre os estudantes das escolas públicas (7,0\%; IC 95\%: 6,6\%-7,5\%) do que entreaquel es das escolas privadas ( $4,0 \%$; IC $95 \%$ : $3,6 \%-4,5 \%)$.

Foram observadas frequências de insegurança no trajeto para a escola menores do que a média das capitais em: Florianópolis (4,3\%; IC95\%: 3,4\%-5,2\%), Porto Velho (4,4\%; IC 95\%: 3,5\%-5,4\%) e Campo Grande (4,5\%; IC $95 \%$ : 3,5\%-4,4\%) (Gráfico 1A).

Tabela 1. Prevalência (erespectivosIC $95 \%$ )* de escolares do 9o ano do ensino fundamental quevivenciaram al gum tipo de situação de violência segundo sexo e dependência administrativa da escola. Capitais brasileiras eD istrito Federal, 2009.

\begin{tabular}{|c|c|c|c|c|c|c|c|c|}
\hline \multirow{3}{*}{$\begin{array}{c}\text { Situação de } \\
\text { violência }\end{array}$} & \multirow{2}{*}{\multicolumn{2}{|c|}{ Total }} & \multicolumn{4}{|c|}{ Sexo } & \multicolumn{2}{|c|}{ Dependência administrativa da escola } \\
\hline & & & \multicolumn{2}{|c|}{ Feminino } & \multicolumn{2}{|c|}{ Masculino } & Privada & Pública \\
\hline & $\%$ & (IC95\%) & $\%$ & (IC95\%) & $\%$ & $(\mathrm{IC} 95 \%)$ & $\% \quad(I C 95 \%)$ & $\% \quad(I C 95 \%)$ \\
\hline $\begin{array}{l}\text { Insegurança no trajeto } \\
\text { casa-escola }\end{array}$ & 6,4 & $(6,1-6,8)$ & 6,0 & $(5,5-6,5)$ & 6,9 & $(6,4-7,5)$ & $4,0 \quad(3,6-4,5)$ & $7,0 \quad(6,6-7,5)$ \\
\hline Insegurança na escola & 5,5 & $(5,2-5,8)$ & 5,0 & $(4,6-5,4)$ & 6,1 & $(5,6-6,6)$ & $2,9 \quad(2,5-3,4)$ & $6,2 \quad(5,8-6,6)$ \\
\hline Briga com agressão física & $12,9($ & $(12,4-13,4)$ & 8,9 & $(8,3-9,4)$ & 17,5 & $(16,7-8,3)$ & $12,6(11,7-3,5)$ & $13,0(12,5-3,6)$ \\
\hline Briga com arma branca & 6,1 & $(5,7-6,4)$ & 3,4 & $(3,1-3,7)$ & 9,0 & $(8,4-9,6)$ & $4,7 \quad(4,2-5,3)$ & $6,4 \quad(6,0-6,8)$ \\
\hline Briga com arma de fogo & 4,0 & $(3,7-4,3)$ & 2,3 & $(2,0-2,5)$ & 6,0 & $(5,5-6,5)$ & $2,6 \quad(2,2-2,9)$ & $4,4 \quad(4,1-4,7)$ \\
\hline $\begin{array}{l}\text { Agredido fisicamente } \\
\text { na família }\end{array}$ & 9,5 & $(9,1-9,9)$ & 10,0 & $(9,4-10,6)$ & 9,0 & $(8,4-9,6)$ & $9,3(8,5-10,1)$ & $9,6(9,1-10,1)$ \\
\hline
\end{tabular}


A frequência de alunos que deixaram de ir à escola porque não se sentiam seguros neste local foi de 5,5\% (IC95\%: 5,2\%-5,8\%), sendo significativamente maior entre os estudantes homens (6,1\%; IC $95 \%: 5,6 \%-6,6 \%)$ do queentremulheres ( $5,0 \%$; IC $95 \%$ : $4,6 \%-5,4 \%)$ e para os matriculados em escolas públicas (6,2\%; IC $95 \%$ : 5,8\%$6,6 \%)$ do que entre aqueles das escolas privadas (2,9\%; IC95\%: 2,5\%-3,4\%) (Tabela 1).

A referência à insegurança na escola foi menor entre os estudantes de Porto Velho $(3,4 \%$; IC 95\%: 2,6\%-4,3\%), Florianópolis (3,6\%; IC 95\%: 2,8\%-4,4\%), João Pessoa (3,8\%; IC95\%: 2,9\%-4,6\%), Natal (3,9\%; IC $95 \%$ : 3,1\%-4,8\%), Porto Alegre (4,1\%; IC95\%: 3,2\%-5,1\%) eVitória $(4,4 \%$; IC $95 \%$ : 3,4\%-5,2\%), enquanto $M$ acapá foi a capital com mai or prevalência de insegurança no ambiente escolar (7,3\%; IC95\%: 6,2\%8,3\%) (Gráfico 1B).

Dentre os escolares entrevistados, $12,9 \%$ (IC95\%: 12,4\%-13,4\%) relataram envolvimento em al guma briga com agressão física nos últimos trinta dias. Esse percentual foi cerca de duas vezes maisalto entreos meninos (17,5\%; IC $95 \%$ : $16,7 \%$ $18,3 \%$ ) do que entre as meninas ( $8,9 \%$; IC $95 \%$ : 8,3\%-9,4\%), evidenciando diferença estatisticamente significativa entre os sexos. $N$ ão houve diferença significativa entre estudantes de escolas públicas (13,0\%; IC $95 \%$ : $12,5 \%-13,6 \%$ ) ou privadas (12,6\%; IC95\%: 11,7\%-13,5\%) (Tabela 1). A maior proporção de envolvimento em brigas com agressão física foi registrada em Curitiba (18,1\%; IC95\%: 16,5\%-19,8\%), Goiânia (15,2\%; IC95\%: 13,8\%-16,6\%) e Rio de Janeiro (14,9\%; IC95\%: 13,5\%-16,3\%). Ascapitais onde se observaram as menores prevalências foram: Teresina (8,4\%; IC 95\%: 7,2\%- 9,6\%), São Luís (9,1\%; IC 95\%: 8,0\%-10,2\%), Porto Velho (9,7\%; IC95\%: 8,3\%-11,1\%), Fortaleza (9,7\%; IC95\%: 8,4\%$11,1 \%)$, M aceió (10,1\%; IC 95\%: 8,7\%-11,5\%), João Pessoa (10,5\%; IC $95 \%$ : 9,1\%-11,9\%) eNatal (10,7\%; IC95\%: 9,4\%-12,0\%) (Gráfico 2).

0 envolvimento em brigas com arma branca foi relatado por $6,1 \%$ (IC 95\%: 5,7\%-6,4\%) dos escolares, com prevalência significativamente maior entre os alunos do sexo masculino $(9,0 \%$; IC 95\%: 8,4\%-9,6\%) do que entre os do sexo feminino (3,4\%; IC95\%: 3,1\%-3,7\%). Também evidenciando diferenças estatisticamentesignificativas, observou-se que mais alunos das escolas públicas se envolveram nesses episódios (6,4\%; IC 95\%: 6,0\%-6,8\%), comparados aos das escolas privadas (4,7\%; IC 95\%: 4,2\%-5,3\%) (Tabela 1). Dentre as capitais estudadas, as maiores prevalências foram registradas em: Boa Vista (9,5\%;
IC95\%: 8,0\%-10,9\%), M acapá (8,5\%; IC95\%: 7,3\%-9,7\%), $M$ anaus (8,4\%; IC95\%: 6,9\%-9,9\%), Curitiba (8,3\%; IC 95\%: 7,1\%-9,5\%), Rio Branco (7,9\%; IC95\%: 6,6\%-9,1\%) e Goiânia (7,7\%; IC95\%: 6,6\%-8,7\%). A menor prevalência foi encontradaem Porto Velho (4,1\%; IC95\%: 3,2\%5,1\%) (Gráfico 3A).

A participação em brigas com arma de fogo foi relatada por $4 \%$ (IC 95\%: 3,7\%-4,3\%) dos estudantes, com identificação de diferenças estatisticamente significativas entre estudantes do sexo masculino (6,0\%; IC 95\%: 5,5\%-6,5\%) em relação ao sexo feminino (2,3\%; IC 95\%: 2,0\%-2,5\%) eentre alunos de escolas públicas ( $4,4 \%$; IC $95 \%$ : 4,1\%-4,7\%) em comparação aos de escolas privadas (2,6\%; IC95\%: 2,2\%-2,9\%) (Tabela 1). As capitais Boa Vista (6,4\%; IC $95 \%$ : 5,2\%-7,6\%), Curitiba (5,9\%; IC $95 \%$ : 4,9\%-6,9\%) e Cuiabá (5,7\%; IC $95 \%$ : 4,5\%-6,8\%) apresentaram as maiores prevalências de escolares envolvidos em brigas com arma de fogo. As menores prevalências foram observadas em Teresina (2,5\%; IC 95\%: 1,8\%-3,2\%), João Pessoa (2,8\%; IC 95\%: 2,0\%$3,6 \%$ ) eM aceió (2,8\%; IC 95\%: 2,0\%-3,6\%) (Gráfico 3-B).

A violência intrafamiliar foi referida por $9,5 \%$ (IC95\%: 9,1\%-9,9\%) dos alunos entrevistados. Não houve diferença estatisticamentesignificativa entre as prevalências observadas entre meninas (10\%; IC 95\%: 9,4\%-10,6\%) emeninos (9,0\%; IC95\%: 8,4\%-9,6\% entre meninos) nem entre escolas privadas (9,3\%; IC $95 \%$ : 8,5\%-10,1\%) e públicas (9,6\%; IC 95\%: 9,1\%-10,1\%) (Tabela 1). Percebe-se que as maiores prevalências de violência física no âmbito doméstico foram registradas em Recife (11,7\%; IC 95\%: 10,3\%-13,0\%) e M acapá (11,6\%; IC95\%: 10,3\%-13,0\%). Florianópolis (6,6\%; IC 95\%: 5,5\%-7,8\%), Porto VeIho (7,2\%; IC $95 \%$ : 6,0\%-8,4\%) e Palmas ( $7,4 \%$; IC95\%: 6,0\%-8,7\%) apresentaram as menores prevalências desse tipo de violência (Gráfico 4).

\section{Discussão}

A PeNSE possibilitou identificar a violência envolvendo o adolescente em diversas situações, e este estudo descritivo buscou, especificamente, fornecer um painel da violência na escola e no deslocamento para ela, além de apresentar marcadores deatitudes eexpressão de violência entre adolescentes (brigas e agressões físicas), formas de exposição consideradas graves e com risco de lesões e mortes (exposição à arma branca e de fogo) e da violência intrafamiliar. 
1A) Insegurança no trajeto casa-escola

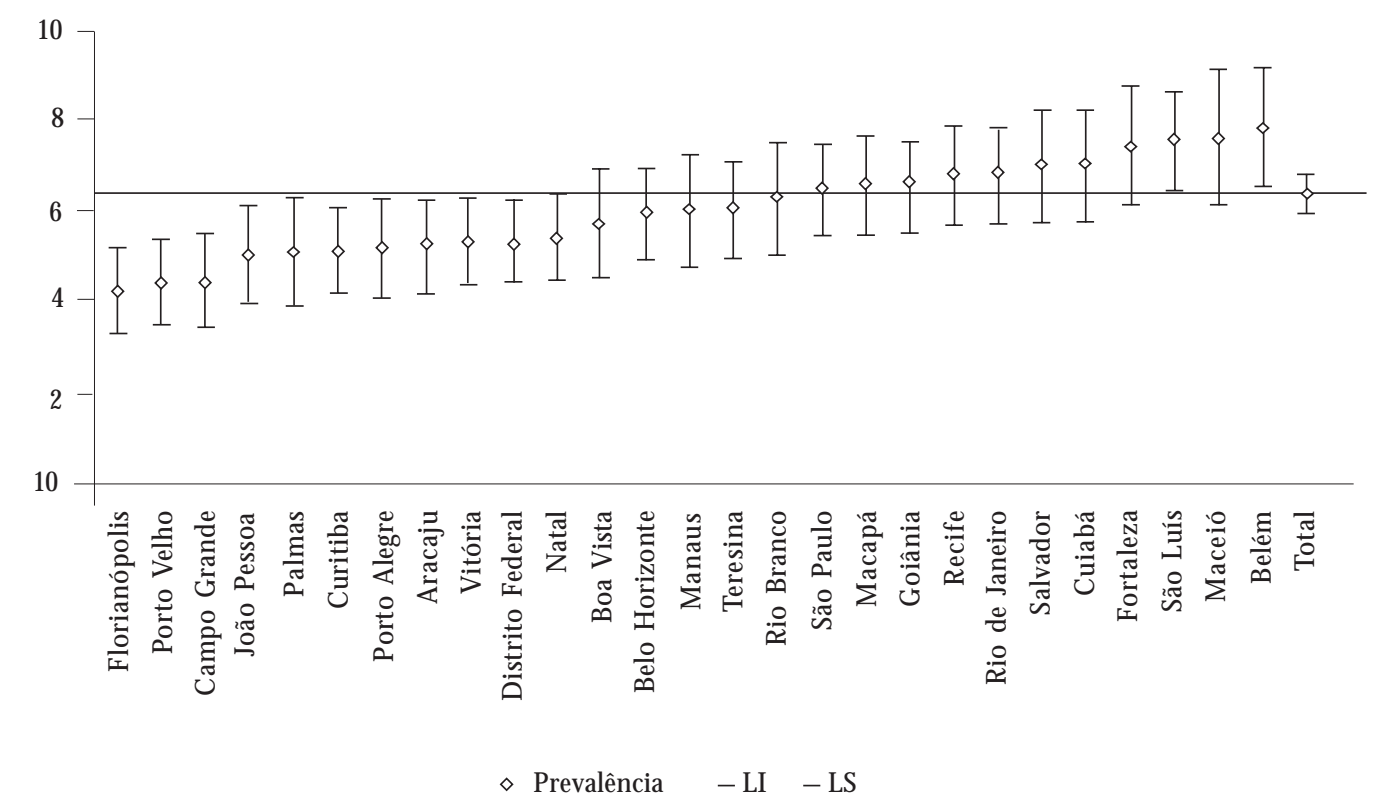

1B) Insegurança na escola

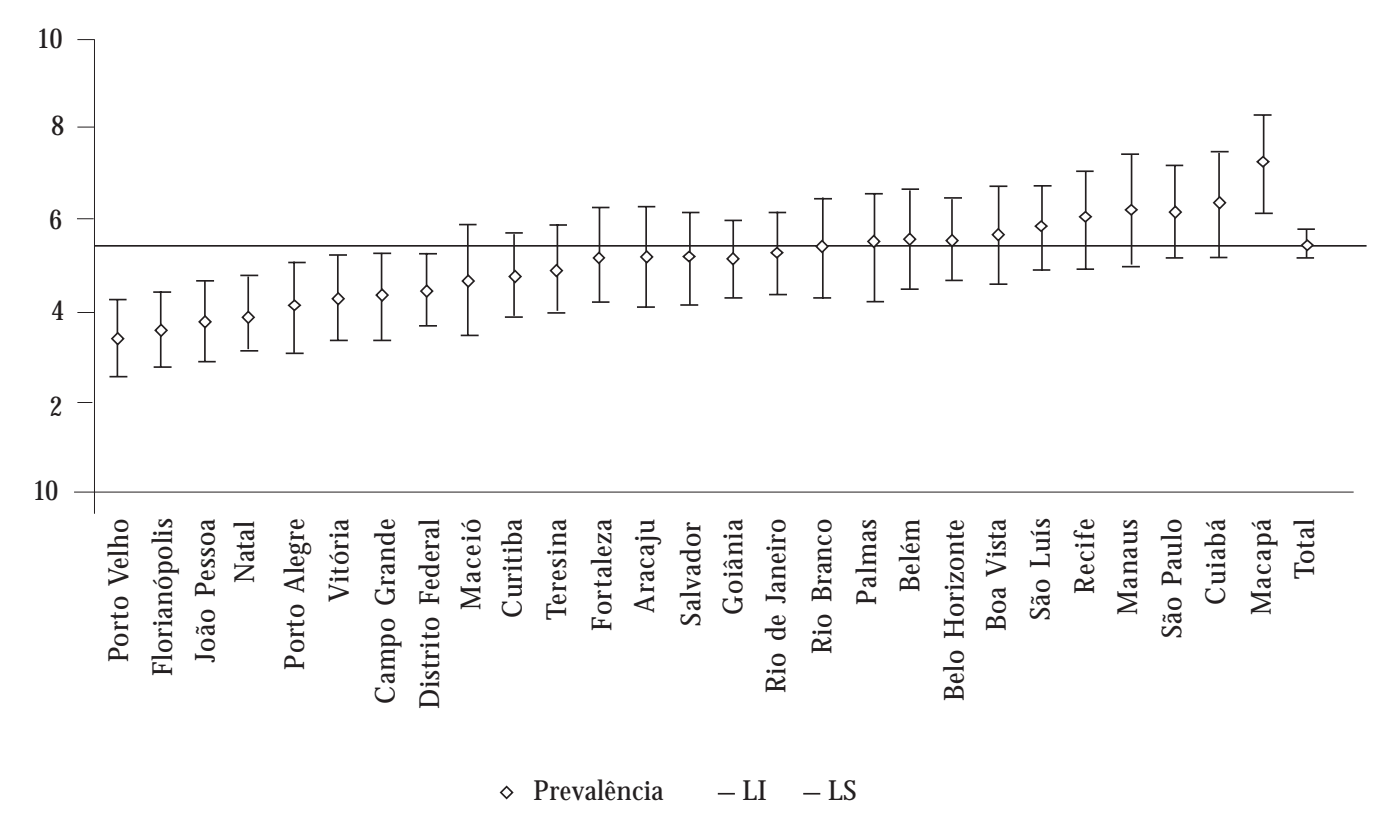

Gráfico 1. Prevalência (e respectivos IC 95\%)* de escolares do 9o ano do ensino fundamental que, nos últimos trinta dias, não compareceram à escola pelo menos uma vez por falta de segurança. Capitais brasileiras e Distrito Federal, 2009.

* Percentual ponderado para representar a população de escolares matriculados efrequentando o 9o ano do ensino fundamental em 2009; IC95\%: intervalo de confiança de 95\%; LI: limite inferior; LS: limite superior. 


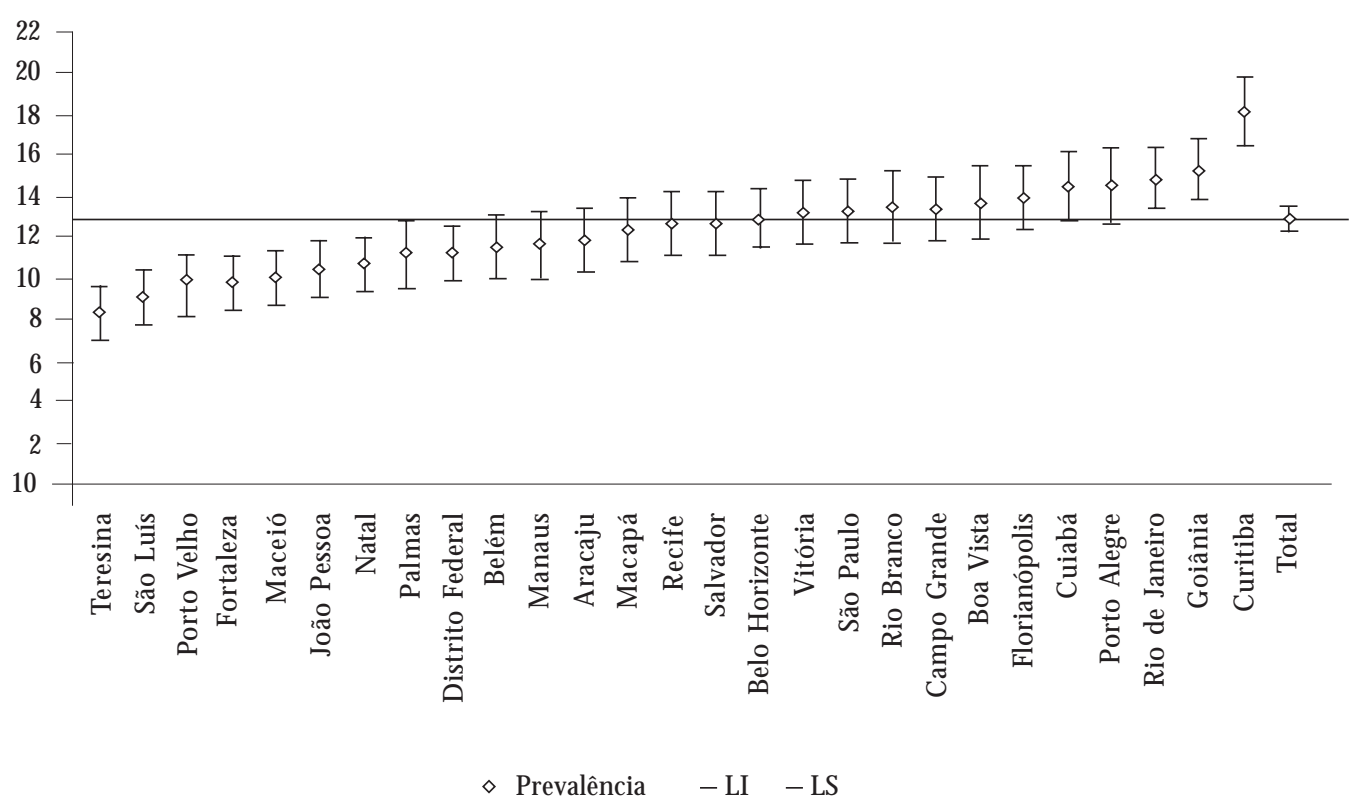

Gráfico 2. Prevalência (e respectivos IC $95 \%$ ) de escolares do 9o ano do ensino fundamental que estiveram envolvidos, nos últimos trinta dias, em alguma briga na qual alguém foi fisicamente agredido. Capitais brasileiras e Distrito Federal, 2009.

* Percentual ponderado para representar a população de escolares matriculados efrequentando o 9 o ano do ensino fundamental em 2009; IC95\%: intervalo de confiança de 95\%; LI: Iimiteinferior; LS: limitesuperior.

No contexto geral, a partir dos dados apre sentados, pode-se afirmar que os estudantes do sexo masculino estiveram mais expostos a situações de insegurança no deslocamento para a escola ena escola, brigas com agressões físicas, envolvimento em brigas com armas branca e de fogo do que os estudantes do sexo feminino. Este achado provavelmente reflete as questões de gênero que permeiam os papéis sexuais esperados elegitimados culturalmente em diferentes sociedades, a partir de um modelo social machista, queéreproduzido inclusiveem faixas etáriasmais jovens, na qual o sexo masculino associa-se à vivência e expressão da agressividade $e^{12,13}$.

Quanto ao tipo de dependência administrativa, houve maior prevalência de insegurança no trajeto e na escola e envolvimento em brigas com arma branca e de fogo entre os alunos de escolas públicas. As escolas públicas estudadas concentram cerca de $80 \%$ dos adolescentes e apresentam maior proporção de mães com baixa escolaridade ${ }^{6}$ (dados não mostrados), refletindo as desigualdades sociais e as iniquidades na distri- buição dos recursos e equi pamentos. Tais características, mais do que conformarem as escolas públicas como espaços violentos, refletem as desigualdades e as iniquidades na distribuição dos recursos e equipamentos sociais, tendendo a re fletir a violência presente no seu entorno, e que muitas vezes a adentra ${ }^{13,14}$.

A PeN SE identificou que $6,4 \%$ dos escolares deixaram de ir à escola porque não se sentiam seguros no caminho de casa para a escola ou da escola para casa e 5,5\% deixaram de ir à escola porque não se sentiam seguros no seu interior. Estas frequências variaram conforme a área de inserção da escola e os riscos inerentes ao território, a ocorrência de violências, a existência degangues, dentre outras situações. Observou-se maior proporção entre alunos de escola pública $(7,0 \%)$ do que nos de escolas privadas $(5,0 \%)$. Tais estratos, público e privado, constituem uma aproximação da renda familiar, expressam desigualdades por local de moradia e mostram a distribuição desigual da violência, com exposiçõese riscos diferenciados, conforme a inserção social. 
3A) Arma branca

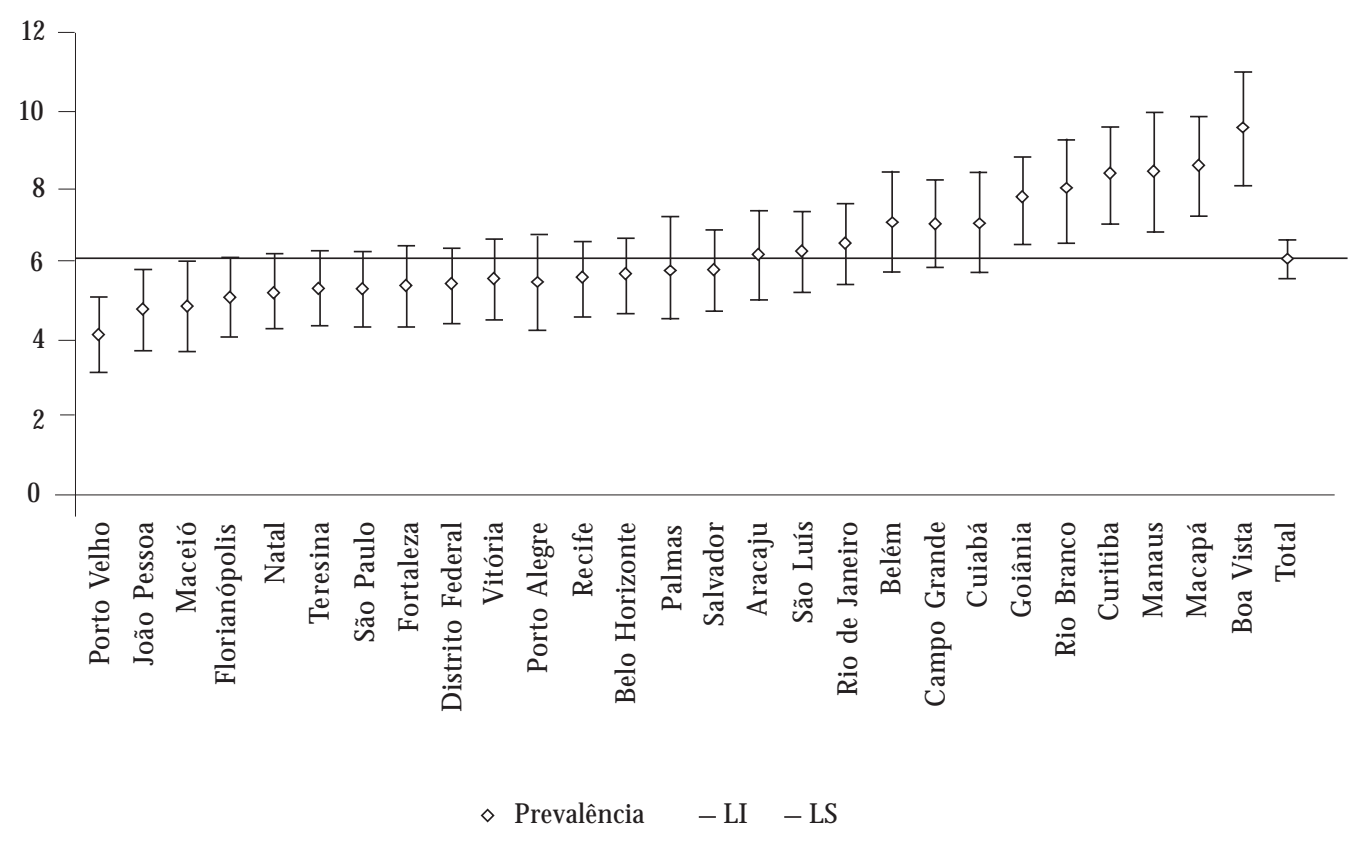

3B) Arma de fogo

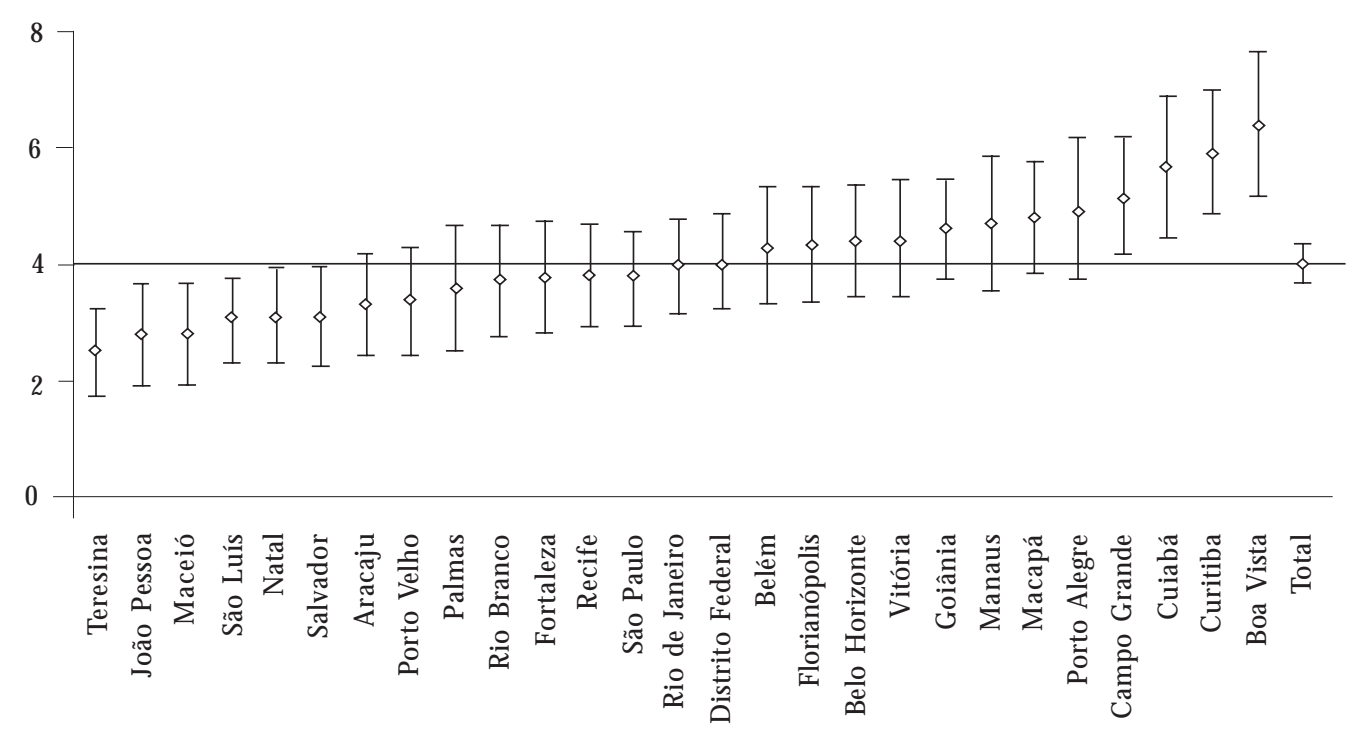

$\diamond$ Prevalência $\quad-$ LI $\quad-$ LS

Gráfico 3. Prevalência (e respectivos IC $95 \%$ )* de escolares do 9o ano do ensino fundamental que estiveram envolvidos, nos últimos trinta dias, em alguma briga na qual alguma pessoa usou arma branca ou arma de fogo. Capitais brasileiras e Distrito Federal, 2009.

* Percentual ponderado para representar a população de escolares matriculados e frequentando o 9o ano do ensino fundamental em 2009; IC95\%: intervalo de confiança de 95\%; LI: limiteinferior; LS: limitesuperior. 


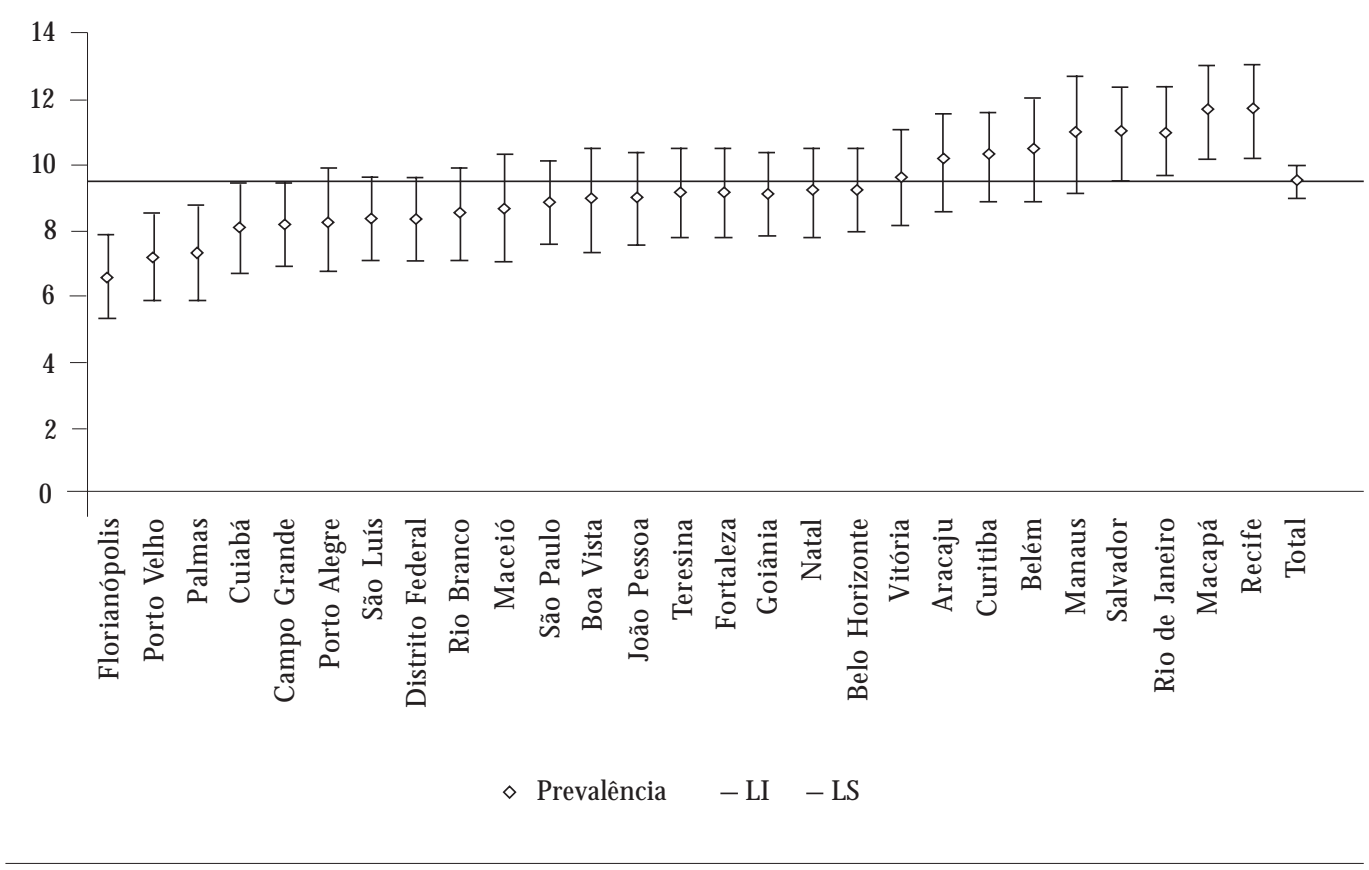

Gráfico 4. Prevalência (e respectivos IC $95 \%$ )* de escolares do 9o ano do ensino fundamental que, nos últimos trinta dias, foram agredidos fisicamente por um adulto da família. Capitais brasileiras e Distrito Federal, 2009.

* Percentual ponderado para representar a população de escolares matriculados efrequentando o 9o ano do ensino fundamental em 2009; IC95\%: intervalo de confiança de 95\%; LI: limiteinferior; LS: limite superior.

Outras pesquisas investigaram a violência sofrida pelos adolescentes no trajeto para a escola, resultante de ambientes inseguros no entorno do estabelecimento de ensino e dos domicílios. Inquérito realizado com estudantes do ensino mé dio nos EUA mostrou que $5,5 \%$ dos alunos deixaram de ir à escola porque não se sentiam seguros no trajeto ou no próprio estabelecimento ${ }^{8}$.

No Brasil, estudo com amostra de 446 alunos e 120 professores, representativo de oito escolas públicas do ensino fundamental e médio do estado do $\mathrm{M}$ aranhão, identificou que $70 \%$ dos alunos não gostam do local (da rua, do bairro e da vizinhança) onde a escola está situada, em razão das gangues que tornam o seu entorno "perigoso". 0 trajeto de casa para a escola e vice-versa e o ponto de ônibus são considerados locais onde a qualquer momento poderá acontecer uma cena de violência. As dependências da escola, demodo geral e, particularmente, a sala de aula são vistas por $22,4 \%$ dos alunos e por $20,8 \%$ dos professores como espaços onde também ocorre violência ${ }^{14}$.

A violência tem emergido como um grande problema entre jovens, sendo a luta física (bri- ga) uma das manifestações mais comuns de violência interpessoal entre adolescentes. Por isso, esse evento foi considerado por especialistas do tema como prioritário e associado à violência interpessoal e às lesões intencionais ${ }^{7,15}$. Estudo da $\mathrm{OM} \mathrm{S}^{7}$ em mais de quarenta países revelou que $14 \%$ dos adolescentes de 13 anos haviam se envolvido em pelo menos três brigas nos últimos 12 meses, sendo maior a proporção entre meninos (21\%) do queentremeninas (7\%). Essasprevalências sereduzem com a idade 7 . $\mathrm{Na}$ Espanha ${ }^{16}$, $56,6 \%$ dos meninos e $23 \%$ das meninas de 13 e 14 anos se envolveram em pelo menos uma briga no último ano. Nos Estados Unidos ${ }^{8}, 35,5 \%$ dos alunos do High School (ensino médio - na faixa dos 14 aos 17 anos) relataram que se envolveram nesses epi sódios nos últimos 12 meses, sendo que $12,4 \%$ das brigas ocorreram dentro da escola. Os ferimentos resultantes precisaram de assistência médica ou de enfermagem em $4,2 \%$ dos casos, demonstrando que foram graves ${ }^{8}$.

Estudo analisando 42 laudos de ocorrência policial em escolas de Campina Grande (PB), identificou que os meninos são as maiores víti- 
mas de violência (62\%) e os colegas foram os perpetradores mais frequentes $(92,9 \%)$. Dentre as lesões mais frequentes, foram identificadas contusões e edemas ${ }^{13}$.

Pesquisa realizada em escolas públicas de São Paul $0^{17}$ revelou queas ocorrências mais frequentes sofridas pelos alunos eram furto ( $48 \%)$, ameaças (36\%), danificação de pertences (33\%) e agressão física (4\%). A prática de atos violentos foi autoassumida por $25 \%$ dos estudantes, manifestada em depredações de patrimônio (25\%) e porte de arma ( $9 \%$ arma branca e $2 \%$ de fogo).

As agressões físicas podem se destacar dependendo do contexto social e do entorno onde a escola está localizada. Estudo realizado na periferia de São Paulo mostrou que a agressão física foi apontada por $47 \%$ dos estudantes, metade tendo ocorrido dentro da escola. Os principais perpetradores foram colegas (56\%), professores (23\%) e funcionários (14\%). 0 roubo foi a segunda ocorrência mais frequente, relatado por $41 \%$ dos alunos ${ }^{18}$.

A PeNSE não abordou temas como furtos e ameaças, mas somente em relação à violência física nos últimos trinta dias anteriores à entrevista. Por isto, toma-se apenas uma referência dos estudos internacionais citados, pela diferença quanto ao tempo considerado. No estudo atual, $12,9 \%$ dos al unos relataram episódios de violência física nos últimos trinta dias, mostrando a grande prevalência dos episódios de briga entre adolescentes. Entre os meninos essa ocorrência foi duas vezes mais frequente do que entre as meninas ( $17,5 \%$ versus $8,9 \%$ ). Não houve diferença entre escolas públicas e privadas, mostrando-se prática comum em ambas, mostrando que a violência entre jovens tem crescido em todas as classes sociais.

Estudo desenvolvido por Camacho ${ }^{19}$, ao comparar instituições de ensino públicas e privadas, apontou o pátio e a sala de aula como os locais mais frequentes para as agressões física ou verbal, respectivamente. A motivação principal para tais agressões é a intolerância contra negros, orientais ehomossexuais nas escolas públicas, econtra aqueles que fogem do padrão estético de altu$\mathrm{ra}$ /peso e de consumo nas escolas privadas.

Inquérito entreadolescentes nos Estados Unidos mostrou que $18 \%$ dos alunos afirmaram portar arma branca e 5,2\% relataram portar arma de fogo nos últimos trinta dias, sendo que $5,9 \%$ dos alunos responderam que levaram as armas brancas para o interior da escola ${ }^{8}$.

Dados da PeN SE indicam que 6,1\% dos escolares se envolveram em brigas com arma branca, quase três vezes mais entre alunos do sexo masculino e cerca de 1,5 vez mais frequente entre os das escolas públicas. As brigas com arma de fogo foram referidas por $4 \%$ dos escolares, sendo mais frequentes entremeninos equase duas vezes mais comuns nas escolas públicas. As agressões físicas, quando acompanhadas de armas, aumentam muito seu potencial deferimentos e letalidade. As causas externas, sobretudo a agressão, têm sido a principal causa de mortalidade entre jovens no Brasil já há algumas décadas4.

Chama a aten ção a presença marcante da violência intrafamiliar, que atingiu cerca de $9,5 \%$ de todos os estudantes entrevistados, independentemente do sexo ou do tipo de escola que frequentava. A violência intrafamiliar foi aqui pesquisada perguntando-se aos escolares sobre sua vivência de agressão física cometida por um familiar adulto. Estetipo de violênciaé, na maioria das vezes, encoberto e revela uma triste realidade: a família, de onde se espera a proteção e o apoio, pode ser uma fonte de violência e agressão. Esse dado aponta ainda para o fato já bem discutido na literatura de que a violência intrafamiliar acontece nos distintos estratos sociais ${ }^{20}$.

A escola pode ser um local privilegiado para a detecção de violência, eo Estatuto da Criança edo Adolescente (ECA) estabelece que todos os profissionais que trabalham com crianças e adolescentes têm o dever de comunicar aos Consel hos Tutelares situações de maus-tratos ${ }^{3}$. No Brasil, o Ministério da Educação implantou o programa Escola que Protege, que tem entre seus objetivos identificar sinais de violência contra as crianças e os adolescentes, visando a sua proteção 21,22 .

Os dados aqui apresentados mostram como os adolescentes estão expostos a/e vivenciam diferentes manifestações de violência nas duas instituições que supostamente deveriam garantir sua proteção e desenvolvimento saudável e seguro a escola e o lar. Esses achados podem incentivar o desdobramento de outros estudos que aprofundem as questões de gênero e as determinações sociais que vitimizam mais os meninos do que as meninas, e em algumas situações mais os estudantes das escolas públicas que os das escolas particulares.

A violência tem crescido entre jovens independentemente de classe social, atingindo jovens de classe média e de segmentos mais privilegiados da sociedade ${ }^{13}$. Os dados aqui descritos de insegurança no trajeto e na escola, bem como a presença de armas em brigas, mais frequentes em escolas públicas, podem se justificar pela localização desses equipamentos nas áreas mais 
violentas das capitais, onde residem esses jovense onde estão inseridos, portanto mais expostos a riscos e situações de violência.

A importância destetrabal ho consisteem apresentar, pela primeira vez, as percepções dos adolescentes brasileiros a respeito da sua exposição à violência, trazendo à tona que a sua exposição e vitimização ocorrem exatamente nos locais on de permanecem grande parte do tempo e revelando que os agressores estão mais perto deles do que seimagina. Esta análisesinaliza para a necessidade deum olhar atento para as situações vivenciadas pelos adolescentes em sua rotina diária. A partir desses achados, tem-se um instrumento valioso para 0 planejamento e o desenvolvimento de ações intersetoriais de prevenção das violências e assistência aos alunos das escolas brasileiras. Devem-se priorizar ações como segurança pública, supervisão dos estudantes no ambienteescolar eacompanhamento psicológico para crianças e adolescentes vítimas de violência no domicílio ena escola.

A PeNSE constitui-se na mais ampla pesquisa em escolares adolescentes no Brasil, entretanto foi realizada em capitais, portanto a realidade de exposição à violência aqui descrita pode não corresponder àquela encontrada em todo o país, em especial nas cidades do interior. Além disto, refere-se a escolares de 9o ano, podendo haver outras diferenças em relação aos adolescentes que não frequentam a escola e em outras faixas etárias. Outra limitação do estudo consiste na apresentação geral dos resultados, pois são marcantes as diferenças nas prevalências de violência entre as capitais estudadas. Desta forma, faz-se necessário o desenvolvimento de análises mais aprofundadas sobre as circunstâncias da violência e seus determinantes sociais, bem como de estudos que identifiquem os principais problemas de cada cidade articulados à sua conjuntura de segurança pública e assistência social.

Estudos têm descrito a perplexidade dos professores para lidar com as situações de conflito nas escolas ${ }^{13}$, tornando fundamental a divulgação desses achados no âmbito da comunidade escolar, envolvendo famílias, professores, diretores e profissionais da educação e saúde em âmbito municipal. 0 tema da violência devetambém ser incluído no planejamento curricular dos cursos de graduação em saúdee educação ${ }^{23}$, visando à sua inserção na formação dos futuros profissionais, para que tenham mais instrumentos para a abordagem nas situações cotidianas de violência.

\section{Colaboradores}

DC M alta trabalhou na concepção e no delineamento do estudo, na análise e interpretação dos dados, redigiu a primeira versão do artigo, trabaIhou na sua revisão crítica e aprovou a versão a ser publicada; ER Souza auxiliou na revisão de literatura e revisão final do texto. M M A Silva, CS Silva eALG Figueroa contribuíram com a revisão de literatura e aprovaram o texto final. C Crespo, MDM M ascarenhas, M AR Andreazzi e DL Porto realizaram a extração ea análise dos dados, a revisão do texto e a formatação final do artigo. OL M orais Neto e GO Penna contribuíram na discussão e na revisão final do texto. 


\section{Referências}

1. World Health Organization (WHO). World report on violence and health. Geneva: WHO; 2002.

2. World Health Organization (WHO). World report on child injury prevention. Geneva: WHO/Unicef; 2008.

3. Lei $n^{\circ} 8.069$, de 13 de julho de 1990. Dispõe sobre o Estatuto da Criança e do Adolescente, e dá outras providências. Diário O ficial da União 1990; 16 jul.

4. Brasil. M inistério da Saúde. Secretaria de Vigilância em Saúde. Departamento de Análise de Situação em Saúde. Saúde Brasil 2007: uma análise da situação de saúde. Brasília: M inistério da Saúde; 2008

5. Brasil. M inistério da Saúde. Secretaria de Vigilância em Saúde. Vigilância de acidentes e violências 2006-2007. Brasília: M inistério da Saúde; 2009.

6. Instituto Brasileiro de Geografia e Estatística (IBGE). Pesquisa Nacional de Saúde do Escolar - PeN SE 2009. Rio de Janeiro: IBGE; 2009.

7. World Health Organization (WHO). Inequalities young people's health: key findings from the $\mathrm{H}$ ealth Behaviour in School-aged Children (HBSC) 2005/2006 survey fact sheet. Copenhagen: WHO [site na Internet] 2008 [acessado 2010 abr 10]. Disponível em: http://www.euro.who.int/D ocument/M ediacentre/ fs_hbsc_17june2008_e.pdf

8. Centers for Disease Control and Prevention (CDC). National Youth Risk Behavior Survey System (YRBSS). Trends in behaviors that contribute to violence. National YRBS: 1991-2007. Atlanta: CDC [site na Internet] 2008 [acessado 2009 set 15]. Disponível em: http://www.cdc.gov/yrbss

9. Instituto Nacional do Câncer (Inca). Vigiescola: Vigilância de Tabagismo em Escolares. Dados e fatos de 12 capitais brasileiras. Brasília: Inca; 2004. v. 1.

10. Castro IRR, Cardoso LO, Engstrom EM, Levy RB, M onteiro CA. Vigilância de fatores de risco para doenças não transmissíveis entre adolescentes: a experiência da cidade do Rio de Janeiro, Brasil. Cad Saude Publica 2008; 24(10):2279-2288.

11. Statistical Package for the Social Sciences for Windows Release 8.0.0. Chicago: SPSS Inc.; 1997. CD-ROM.

12. Guimarães NM, Pasian SR. Agressividade na adolescência: experiência e expressão da raiva. Psicol Estud 2006; 11(1):89-97.

13. Cavalcanti AL. Lesões no complexo maxilofacial em vítimas de violência no ambiente escolar. Cien Saude Colet 2009; 14(5):1835-1842.

14. Macedo RM A, Bomfim M CA. Violências na escola. Rev Diálogo Educ 2009; 9(28):605-618.

15. Nansel TR, Overpeck MD, Haynie DL, Ruan WJ, Scheidt PC. Relationships between bullying and violence among US youth. Arch Pediatr Adolesc M ed 2003; 157(4):348-353.
16. Rodríguez M CM, Tinoco M VM, M oreno PJP, Queija IS. Los adolescentes españoles y su salud: resumen del estúdio $\mathrm{H}$ ealth Behaviour in School Aged Children (HBSC-2002). M adrid: M inisterio de Sanidad y Consumo/Universidad de Sevilla [site na Internet] 2005 [acesso em 2009 nov 15]. Disponível em: http:/ /www.hbsc.org/countries/downloads_countries/ Spain/adolesResumen2005.pdf

17. Abramovay $M$, Rua M G. Violências nas escolas. Brasília: Unesco; 2002.

18. Domingos B. Escola e violência: configurações da violência escolar segundo alunos, professores, pais e moradores da comunidade [tese]. São Paulo: Instituto de Psicologia; 2005.

19. Camacho LMY. As sutilezas das faces da violência nas práticas escolares de adolescentes. Educ Pesqui 2001; 27(1):123-140.

20. 20. M inayo MCS, Assis SG, Souza ER, N jaine $K$, Deslandes SF, Silva CM FP, Fraga PCP, Gomes R, Abramovay M, Waiselfisz J, M onteiro MCNI. Fala Galera: juventude, violência e cidadania no Rio de Janeiro. Rio de Janeiro: Garamond; 1999.

21. Brasil. M inistério da Educação. Secretaria de Educação Continuada, Alfabetização e Diversidade. Proteger para educar: a escola articulada com as redes de proteção de crianças e adolescentes. Brasília: M inistério da Educação; 2007.

22. Brasil. M inistério da Educação. Programa Escola que Protege. Braślia: M inistério da Educação [site na Internet] 2010 [acessado 2010 maio 20]. Disponível em: http://portal.mec.gov.br/index.php?option $=$ com_content $\&$ view $=$ article $\& i d=12363 \&$ I temid $=565$

23. Souza ER, Ribeiro AP, Penna LHG, Ferreira AL, Santos NC, Tavares CM M. O tema violência intrafamiliar na concepção dos formadores dos profissionais de saúde. Cien Saude Colet 2009; 14(5):1709-1719.

Artigo apresentado em 30/05/2010

Aprovado em 21/06/2010

Versão final apresentada em 27/07/2010 